\title{
Factors Influencing Consumer Usage of Luxury Brand: Empirical Evidence from Bangladesh
}

\author{
[ Mohammad Osman Gani, Mohammad Masud Perves , Md. Hasan Ali]
}

\begin{abstract}
Factors influencing consumer usage of luxury brand in the context of developing country like Bangladesh is new but it has already been applied in the developed country. Luxury brand is now available to the individuals other than the elite and rich class. The factors which influence the consumer of Bangladesh are the main concern of this paper. For accomplishing this research, convenience sampling procedure had been applied on 219 respondents. For the purpose of testing the hypothesized associations, KMO and Bartlett's test, Coefficient, Total variance, ANOVA and finally the model has been applied to justify the conceptual framework through using SPSS. The study found that five factors (financial, functional, individual, social and cultural) including sub-factors have significant influence on usage of luxury branded products.
\end{abstract}

Keywords - Luxury brand, different factors, KMO, Bartlett's test, ANOVA.

\section{Introduction}

Luxury can be defined as a prestigious brand encompassing several physical and psychological values .Luxury brands are widely used to represent categories of exclusive, high-priced, often extravagant goods and services that are more likely to be purchased by upper income individuals. People are now becoming more status -seeking and want to place themselves in a position where he or she can attract others through their standard of living. People think that only luxury products can make them to feel unique and different from others. In Bangladesh, middle class people are becoming more conscious about the standard of living. One of the most important factors leading to the actual growth of the luxury market is the introduction of luxury goods to the middle and upper-middle class (Sathyanarayan 2014:84). Luxury products come up with different issues like price, quality, usability, uniqueness, self-identity, prestige, social-status etc.

\section{Mohammad Osman Gani \\ Lecturer, Department of Marketing \\ Faculty of Business Studies \\ Bangladesh University of Professionals (BUP)}

\section{Mohammad Masud Perves \\ Assistant Professor, Department of Accounting \\ Faculty of Business Studies \\ Dhaka Commerce College}

\section{Md. Hasan Ali}

Assistant Professor, Department of Accounting

Faculty of Business Studies

Dhaka Commerce College
Apart from this, other factors like cultural related such as income, religion and gender also play a great role in choosing luxury products. Financial dimension like price, resale, discount also influence the usage of a luxury brand . Above all, the demand of a luxury product depends more on the reputation of a brand. Religious perspectives; its rulesregulations also impacts in making purchasing decision of a luxury product. Women are more concerned about their prestigious and uniqueness issue than men.

\section{Problem Identification}

In different research work, it has been found that many works on luxury brand have been undertaken mainly in developed country. Bangladesh is a developing country and the demand for luxury goods are increasing. So, this research work wants to show that how the different factors influence the usage of luxury products in the context of Bangladesh and which factor has more influence on usage of luxury brand.

\section{Research Objectives}

The prime purpose of this study is to find out and understand various factors influencing the usage of luxury brand in Bangladesh.

\section{Specific Objectives}

1) To identify different factors which influence the usage of luxury brand?

2) To understand how different factors influence the usage of luxury brand in Bangladesh.

3) To identify which factor has more influence in usage of luxury brand in Bangladesh.

\section{Research Questions}

RQ1. Do the financial factors impact on luxury brand usage?

RQ2. Does the functional factors influence luxury brand usage?

RQ3. Do the individual factors impact on luxury brand usage?

RQ4. Do the social factors impact on luxury brand usage?

RQ5. Do the cultural factors impact on usage of luxury brand?

\section{Literature Review}

There are different views in literature on the definition and scope of "luxury". The word "luxury" is derived from the Latin word "luxus" and according to its definition in Latin Oxford Dictionary, it refers to "soft or extravagant living, overindulgence" and "sumptuousness, comfort, abundance" (Christodoulides et al. 2008: 397). Luxury brands can be defined as those whose price and quality ratios are the highest of the market (McKinsey 1990) and even though the 
ratio of functionality to price might be low with regard to certain luxury goods, the ratio of intangible and situational utility to price is comparatively high (Nueno and Quelch 1998) Therefore, luxury brands compete on the ability to evoke exclusivity, brand identity, brand awareness and perceived quality in the consumer's perspective (Phau and Prendergast 2000).

In the work of (Wiedmann, Hennigs and Siebels et al.,2015), he has included all relevant dimensions like financial, functional, individual and social which helps to understand customer perception. According to the work of (Atwal Eric et al., 2009); cultural factors influence consumer's buying behavior and this all factors have been combined with sub factors to better understand the influence of luxury brand and the factors.

a) Financial factors- Financial dimension addresses direct monetary aspects such as price, resale price, discount, investment, etc.

b) Price- To judge quality, status-conscious consumers like to use price cue also as an indicator of prestige

c) Income- Higher income wage earners may have the economic resources to buy expensive products, but high levels of personal spending control restrict by themselves (Bearden \& Haws, 2012).

d) Functional factors - Luxury value such as the quality, uniqueness, usability, reliability and durability of the product are the functional factors (Sheth et al. 1991).

e) Usability-Generally, a product or a service is designed to perform a particular function to satisfy consumer needs.

f) Quality - Consumers buy luxury brands is because of the superior quality what possess with brand name.

g) Uniqueness-Uniqueness is based on the assumption that the exclusivity and rareness of a limited product enhances the consumer's desire or preference for a brand.

h) Individual factors - The individual dimension focuses a customer's personal perception about luxury consumption and addresses personal matters such as materialism, hedonistic and self-identity value.

i) Social factors-Social dimension refers to the perceived utility that individuals acquire by consuming products or services recognized within their own social group(s), which may significantly affect the evaluation and the propensity to purchase or consume luxury brands.

j) Hedonism-Certain products and services carry an emotional value and provide intrinsic enjoyment in addition to their functional utility.

k) Materialistic- Researchers have interpreted materialism from different perspectives, theorists have not yet agreed on a single definition. Highly materialistic individuals tend to devote more time and energy to product related activities (Belk 1985).

1) Self-Identity-Self-identity refers to the internal (private) facet of one's self in terms of the way the individual perceives him or herself. m) Conspicuousness - Luxury brands may be important to individuals in search of social status and representation and means in particular that the ranking in a society associated with a brand plays an important factor in conspicuous consumption.

n) Prestige-Much of the existing research has emphasized on the role of status that has an impact in communicating information about their possessors and social relationships

o) Cultural value- Consumer behavior is highly influenced by cultural factors and has been addressed as fundamental determinant of person's want and behavior. He has identified that sub-culture is member of culture and shares most of the core values, beliefs and behavior of that culture.

p) Religion: Religious commitment plays an important role in people's lives by shaping their beliefs, knowledge, and attitudes.

q) Gender: Purchasing data based on gender reveals that women purchase more clothing and accessory items than men do.

r) Behavior: Luxury products can lead consumers to engage in behaviors that are highly valued by society and also identified that who wear or simply imagine themselves wearing luxury products subsequently work harder at difficult task, donate time and money to charity, and are willing to pay more to help local businesses.

Based on the literature review, some hypotheses have been developed to better understand the factors which have influence in usage of luxury brand in Bangladesh.

$\mathbf{H}_{10}$ : Financial factors have no influence in usage of luxury brand

$\mathbf{H}_{11 \text { : }}$ Financial factors have influence in usage of luxury brand

$\mathbf{H}_{\mathbf{2 0}}$ : Functional factors have no influence in usage of luxury brand

$\mathbf{H}_{21}$ : Functional factors have influence in usage of luxury brand

$\mathbf{H}_{30}$ : Individual factors have no influence in usage of luxury brand

$\mathbf{H}_{31}$ : Individual factors have influence in usage of luxury brand

$\mathbf{H}_{40 \text { : }}$ Social factors have no influence in usage of luxury brand

$\mathbf{H}_{41}$ : Social factors have no influence in usage of luxury brand

$\mathbf{H}_{50 \text { : }}$ Cultural factors have no influence in usage of luxury brand

$\mathbf{H}_{51}$ : Cultural factors have no influence in usage of luxury brand 
Figure 1: Conceptual Framework

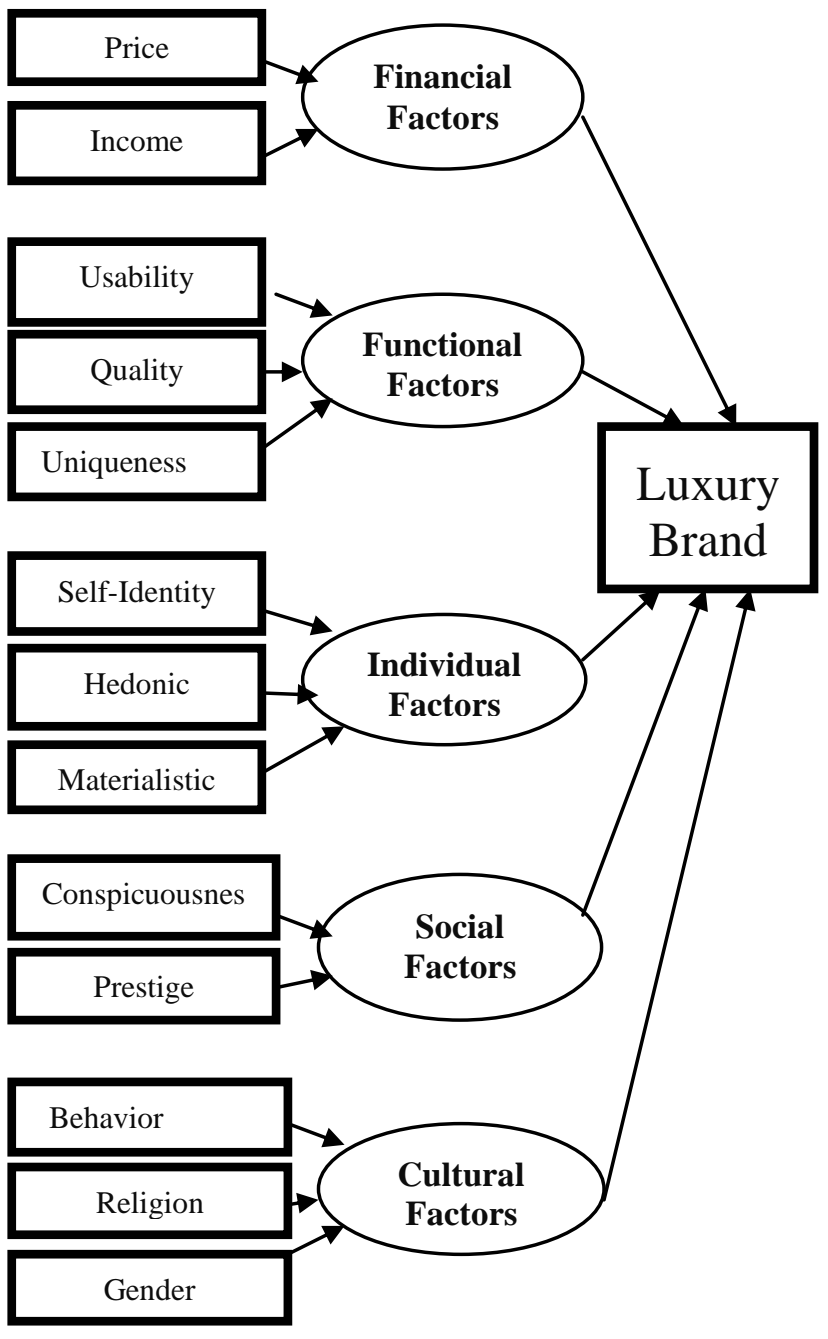

Source: Developed by authors.

\section{Methodology}

This research basically a quantitative research, particularly descriptive research design was used to accumulate data to investigating the influence of different factors on luxury brand in Bangladesh in addition with relationships among those pre-specified variables by means of research hypotheses. A sample of 219 was selected for the purpose of the study. In this study, a survey questionnaire was designed as to know the influence of different factors on the usage of luxury brand. Respondents were asked questions relating to their overall perception about factors on the usage of luxury brand on a 5 point Likert-type scale anchored by Strongly Disagree and Strongly Agree. No affect to Major affect on 5 point Likert scale has also been used. Financial, functional, individual, social and cultural factors were considered as independent variables where the luxury brand was considered as dependent variables.

\section{Data Analysis and Results}

\section{a. Reliability Test}

Scale reliability was tested using Cronbach alpha scores, the values of which were calculated for each scale to test for internal consistency. The scale reliability test has been done through SPSS version 19. All constructs appeared to be robust and acceptable as they exceeded Nunnally's (1967) threshold of 0.70 . (Financial factors, $\mathrm{a}=.706$, Functional factors, $\mathrm{b}=.703$, Individual factors, $\mathrm{c}=.789$, Social factors, $\mathrm{d}=.810$, Cultural factors, $\mathrm{e}=.720$.)

\section{A. KMO (Kaiser-Meyer-Olkin)}

Table 1: KMO \& Bartlett's Test

\begin{tabular}{|lll|l|}
\hline $\begin{array}{l}\text { Kaiser-Meyer-Olkin } \\
\text { Adequacy. }\end{array}$ & Measure & of Sampling & .796 \\
& & & \\
& $\begin{array}{l}\text { Approx. Chi- } \\
\text { Square }\end{array}$ & 934.380 \\
Bartlett's Test of Sphericity & df & 105 \\
& Sig. & .000 \\
\hline
\end{tabular}

From the KMO (Kaiser-Meyer-Olkin) measure of sampling adequacy and Bartlett's Test of sphericity, it is found that factor analysis is significant. If the value of KMO test is above .5 and Bartlett's Test is below .5 then it can be statistically concluded that factor analysis is significant. In this case, KMO is greater than .5 and BARTLETT's test is below .5 which implies the accuracy of factor analysis.

\section{B. Coefficients}

\begin{tabular}{|c|c|c|c|c|c|}
\hline \multirow[t]{2}{*}{ Model } & \multicolumn{2}{|c|}{$\begin{array}{l}\text { Unstandardized } \\
\text { Coefficients }\end{array}$} & \multirow{2}{*}{$\begin{array}{l}\text { Standardized } \\
\text { Coefficients } \\
\text { Beta }\end{array}$} & \multirow[t]{2}{*}{$t$} & \multirow[t]{2}{*}{ Sig. } \\
\hline & B & $\begin{array}{l}\text { Std. } \\
\text { Error }\end{array}$ & & & \\
\hline $\begin{array}{l}\text { (Constant) } \\
\text { 3. Do you agree that } \\
\text { income has } \\
\text { influence in using } \\
\text { luxury brand? } \\
6 . \text { Do you agree } \\
\text { that Uniqueness has } \\
\text { influence in using } \\
\text { luxury brand? } \\
8 . \text { Do you agree } \\
\text { that self- identity } \\
\text { enhances by using } \\
\text { luxury brand? }\end{array}$ & 1.657 & .269 & -.008 & 6.168 & .000 \\
\hline
\end{tabular}




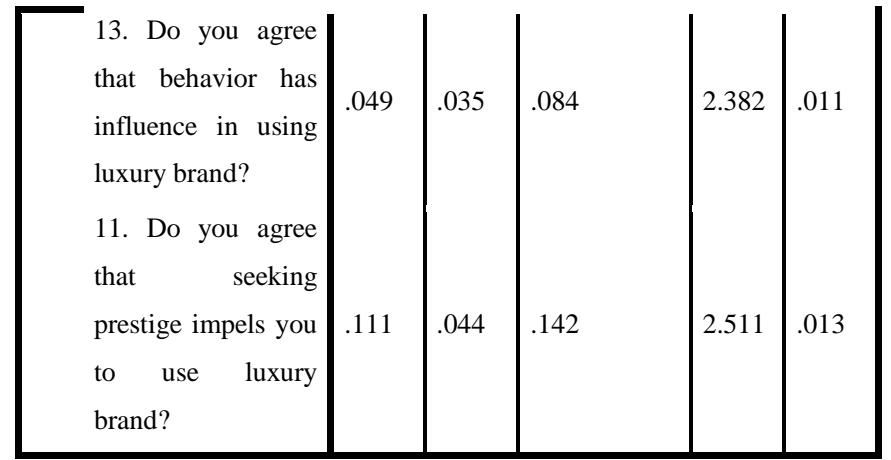

a. Dependent Variable: Usage of Luxury Brand

From the co-efficient table, it can be conferred that all the selected surrogate variables (1. Income-Do you agree that income has influence in using luxury brand? 2 . Uniqueness-Do you agree that Uniqueness has influence in using luxury brand? 3. Self-identity-Do you agree that selfidentity enhances by using luxury brand? 4. Prestige-Do you agree that seeking prestige impels you to use luxury brand? 5. Behavior- Do you agree that behavior has influence in using luxury brand?) from the factors namely financial, functional, individual, social and cultural are significant according to the 5\% level of significance and it is also proven from the column $t$ of the co-efficient table. It means that all the predictors from all the factors have influence in the use of luxury brand. From the factor loading, it has been identified that there is strength of association between predictors and usage of luxury brand.

The output shows the results of fitting a multiple linear regression model to describe the relationship between usage of luxury brand and 5 independent variables. The equation of the fitted model is-

$$
\begin{array}{ll}
\mathbf{Y}=\boldsymbol{\beta}_{0}+\beta_{1} X_{1}+\beta_{2} X_{2}+\beta_{3} X_{3}+\beta_{4} X_{4} \\
\text { where, } \\
\begin{array}{ll}
Y= & \text { Usage of luxury brand } \\
& \\
X_{1}=\text { Income } & X_{3}=\text { Self-identity } \\
X_{2}=\text { Uniqueness } & X_{4}=\text { Prestige } \\
& X_{5}=\text { Behavior }
\end{array}
\end{array}
$$

With the value of coefficients the model is as follows:

$$
\begin{aligned}
\Rightarrow & \mathrm{Y}=1.657+0.007 \mathrm{X}_{1}+.180 \mathrm{X}_{2}+0.269 \mathrm{X}_{3}+.111 \mathrm{X}_{4} \\
& +0.049 \mathrm{X}_{5} \\
\Rightarrow & \text { Performance }=1.657+0.007 * \text { Income }+ \\
& .180 * \text { Uniqueness }+.269 * \text { Self-identity }+ \\
& .111 * \text { Prestige }+.049 * \text { Behavior }
\end{aligned}
$$

The value of coefficients ( $\beta$-Value) was explained by the following:

$\boldsymbol{\beta}_{0}=1.657$ (Constant) whatever the increment or decrease in any other predictors i.e. income or uniqueness or self-identity or prestige or behavior; the usage of luxury brand will always be constant at this value $\left(\beta_{0}=.002\right)$.

$\boldsymbol{\beta}_{1}=0.007$ shows that for 1 unit increase in income will increase the usage of luxury brand. $\boldsymbol{\beta}_{\mathbf{2}}=0.180$ signifies that for one unit increase in uniqueness there will be about 0.180 times increase in luxury brand.

$\boldsymbol{\beta}_{\mathbf{3}}=0.269$ states that for one unit increase in selfidentity, the usage of luxury brand will increase by 0.269 times.

$\boldsymbol{\beta}_{\mathbf{4}}=0.111$ signifies that for one unit increase in prestige, the usage of luxury brand will increase by 0.111 times.

$\boldsymbol{\beta}_{5}=0.49$ signifies that for one unit change in the behavior in a positive way, the usage of luxury brand will increase by 0.49 times.

\section{d. Model Summary}

\begin{tabular}{|l|l|l|l|l|}
\hline Model & R & R Square & $\begin{array}{l}\text { Adjusted } \\
\text { R Square }\end{array}$ & $\begin{array}{l}\text { Std. Error of } \\
\text { the Estimate }\end{array}$ \\
\hline 1 & $.571^{\mathrm{a}}$ & .740 & .758 & .242 \\
\hline
\end{tabular}

a. Predictors: (Constant), 3.Do you agree that income has influence in using luxury brand? 8. Do you agree that self-identity enhances by using luxury brand? 6 . Do you agree that Uniqueness has influence in using luxury brand? 13. Do you agree that behavior has influence in using luxury brand? 11. Do you agree that seeking prestige impels you to use luxury brand?

b. Dependent Variable: Usage of Luxury Brand

From the model summary, as the adjusted R square is beyond .5 so we can statistically arrived at the point that the regression is significant where standard error of the estimate is minimum with .242 .

\section{e. ANOVA Test}

\begin{tabular}{|l|l|l|l|l|l|}
\hline \multicolumn{1}{|c|}{ Model } & \multicolumn{1}{|c|}{$\begin{array}{c}\text { Sum of } \\
\text { Squares }\end{array}$} & Df & $\begin{array}{l}\text { Mean } \\
\text { Square }\end{array}$ & F & Sig. \\
\hline Regression & 62.41 & 5 & 12.482 & 23.483 & $.000^{\mathrm{b}}$ \\
Residual & 129.164 & 243 & .532 & & \\
Total & 191.574 & 248 & & & \\
\hline
\end{tabular}

\section{a. Dependent Variable: Usage of Luxury Brand}

b. Predictors: (Constant), 6. Do you agree that Uniqueness has influence in using luxury brand? 13. Do you agree that behavior has influence in using luxury brand? 3. Do you agree that income has influence in using luxury brand? 8. Do you agree that self-identity enhances by using luxury brand? 11. Do you agree that seeking prestige impels you to use luxury brand?

From the table, it can be said that regression is significant because it is clear from the ANOVA table that F statistics signifies the result and it is accepted under 5\% significance level.

The findings from this research revealed that financial factors have influence on usage of luxury products $\left(\mathbf{H}_{11}\right)$. It has already been found in the developed countries like 
Bangladesh, income plays a great role in usage of luxury products. It shows a significant role in the financial factor segment.

According to another finding, it clearly revealed that functional factors have influence in usage of luxury products $\left(\mathbf{H}_{21}\right)$. From the survey it has been found that people want to use luxury products based on the feature of usability. It shows more significant effect other than two factors (quality and uniqueness). Likewise, Individual factors also have an influence in usage of luxury products $\left(\mathbf{H}_{31}\right)$. Besides others, hedonic and materialistic; self-identity shows more significance in the factor of individual. Nowadays, people are becoming more biased with the fashion and own identity and in this segment, luxury products play a great role. Selfidentity has been given more priority other than time and energy given toward buying a luxury product. Social factors with conspicuousness and prestige factors also give an impact in using luxury product $\left(\mathbf{H}_{41}\right)$. Prestige issue shows more significance than conspicuousness factor. Likewise, cultural factors along with behavior, religion and gender play an important in the usage of luxury products $\left(\mathbf{H}_{51}\right)$. In this part, behavior has shown more significance level other than two. As all the factors have achieved the level of significance so it can be said that these five factors have an influence in usage of luxury product of consumers in Bangladesh.

\section{Limitations}

In spite of achieving all objectives, a few limitations were addressed throughout this study. First of all, as the sample size of the study $(n=219)$ was small so it does not reflect the overall perception of people about the influence on factors. Secondly, the sample was collected mainly from the graduate and postgraduate students between ages of 23 and 30 besides other education level respondents with different age levels were there but they were in limited percentage so it overlooked the diversity of the respondents.

\section{Future Directions}

As the sample size of this study $(\mathrm{n}=219)$ is not representative considering the population size of Bangladesh. So, large sample size in different context is needed to justify the model. More factors and more predictors under these factors to provide a better understanding of how different factors influence the usage of luxury brand in Bangladesh.

\section{Conclusion}

As Bangladesh is a developing country and people of this country are not very used to with the use of luxury products but recently the trend is changing as the living standard is increasing with positive ratio. People are becoming more fashion conscious and upper middle class and middle class people are coming toward using the luxury branded product.So, different factors have the influence on purcahsing of luxury items.

\section{References}

[1] Atwal, Glyn and Alistair Williams,"Luxury Brand Marketing- The Experience Is Everything!," Journal of Brand Management, 16(March-May),338-46. 2009
[2] Bearden, William O. and Michael J. Etzel. Reference group influence on product and brand purchase decisions.Journal of Consumer Research 9 (2): 183194.1982

[3] Belk, Russell W., "Hyperreality and globalization: Culture in the age of Ronald McDonald", Journal of International Consumer Marketing 8 (3 and 4): 2332,1995 .

[4] Christodoulides, George; Michaelidou, Nina; Li, Hsing Ching. "Measuring Perceived Brand Luxury: An Evaluation of theBLI Scale. Brand Management", 16, 5/6, September, 397. 2008.

[5] McKinsey. "The Luxury Industry: An Asset for France. Paris: McKinsey", 1990.

[6] Nueno, Jose L. and John A. Quelch.-The mass marketing of luxury.\| Business Horizons 41 (6): 61-68. 1998

[7] Phau I., \& Teah M. Devil wears (counterfeit) Prada: a study of antecedents and outcomes of attitudes towards counterfeits of luxury brands. The Journal of Consumer Marketing 26(1): 15-27. 2009.

[8] Savitha, S;Sathyanarayan, K. "Taxonomy of Luxury Brand Value. Research Explorer", (III/8), January June, 86. 2014.

[9] Sheth, Jagdish N., Bruce I. Newman, and B. I. Gross. - "Why we buy what we buy: A theory of consumption values", Journal of Business Research 22 (1): 159-170. 1991.

[10] Wiedmann, Hennigs and Siebels "Measuring Consumers' Luxury Value Perception: A Cross-Cultural Framework". [Online] (7).Available from: http://s1.downloadmienphi.net/file/downloadfile4/147/1 389999.pdf.,2007.

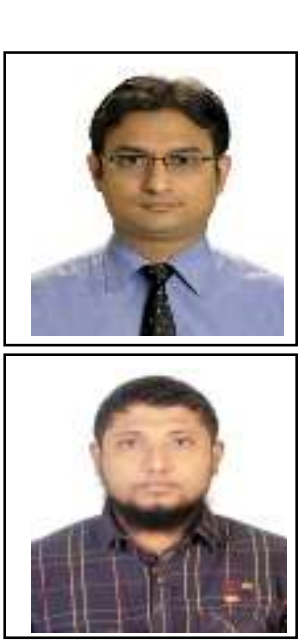

About Author(s)

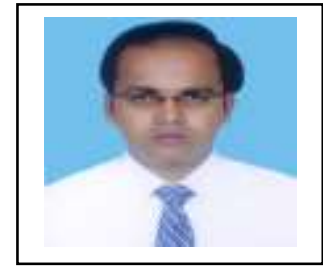

Mohammad Osman Gani has been serving as Lecturer of the Faculty of Business Studies (FBS) in Bangladesh University of Professionals, Mirpur Cantonment, Dhaka, Bangladesh. $\mathrm{He}$ is a graduate of Dhaka University. Also, he is an M.Phil Researcher at BUP.

Mohammad Masud Perves has been serving as an Assistant Professor of the Department of Accounting in Dhaka Commerce College, Mirpur ,Dhaka, Bangladesh. He is a graduate of National University. He has numerous publications in different national and international journals.

Md. Hasan Ali has been serving as an Assistant Professor of the Department of Finance and Banking in Dhaka Commerce College, Mirpur ,Dhaka, Bangladesh. He is a graduate of National University. Also, he is an M.Phil Researcher at BUP. 